\title{
Critical Access Hospital (CAH) Graduate Medical Education (GME): Too Little, and Maybe Too Late
}

\author{
Frederick M. Chen, MD, MPH
}

In the context of national scrutiny on graduate medical education (GME) from both the Medicare Payment Advisory Commission and the Joint Select Committee on Deficit Reduction, ${ }^{1}$ Xierali et $\mathrm{al}^{2}{ }^{2}$ bring our attention to the ongoing needs of rural underserved communities and the potential role of critical access hospitals (CAHs) in training the rural physician workforce. Their analysis demonstrates the miniscule number of CAHs that have reported resident training within their walls. The literature shows that physician training in rural settings is successful in producing rural physicians but also is endangered with the number of rural training tracks and rural residencies in free-fall over the past 10 years. $^{3}$

Although CAHs may be an untapped resource for GME, there are significant barriers to their success. Xierali et $\mathrm{al}^{2}$ point out the challenges of accreditation and staffing. CAHs, like RTTs, are by definition located in small communities that tend to be under-resourced for physician faculty and other medical education needs. Often the loss of a single physician in these settings results in the loss of the training site.

Financing is always an important consideration. Though CAHs may be eligible for Medicare GME

Submitted 27 October 2011; revised 27 October 2011; accepted 27 October 2011.

From the Department of Family Medicine, University of Washington School of Medicine, Seattle.

Funding: none.

Conflict of interest: none declared.

Corresponding author: Frederick Chen, Department of Family Medicine, University of Washington School of Medicine, Box 4311, 11th Avenue NE, Suite 210, Seattle, WA 98195-4982 (E-mail: fchen@u.washington.edu).

doi: $10.3122 /$ jabfm.2012.01.110301 payments because they are free of the resident cap, many CAHs have a low percentage of Medicare inpatients, resulting in payments that are insufficient to cover the costs of residency training. On the other hand, this has not precluded urban hospitals from claiming the time that residents spend in CAHs. Though this enables some residency training time in CAHs, the flow of funds, if any, from the urban hospital to the CAH is unknown, except to hospital financial officers.

Enabling and encouraging more residency training in rural settings is a priority if rural communities are to have adequate access to health care. New training models that encourage community-based training also encourage CAHs to participate in physician training. However, changes to GME financing are needed if CAHs are going to be able to play a larger role in rural physician training.

\section{References}

1. Iglehart JK. The uncertain future of Medicare and graduate medical education. N Engl J Med 2011; 365:1340-5.

2. Xierali I, Sweeney S, Phillips R, Bazemore A, Petterson S. Increasing graduate medical education in critical access hospitals could enhance physicians recruitment and retention in rural America. J Am Board Fam Med 2012;25:7-8.

3. Chen FM, Andrilla CHA, Doescher MP, Morris C. Family medicine residency training in rural locations. Final report \#126. July 2010. Available at http://depts.washington.edu/uwrhrc/uploads/RHRC_ FR126_Chen.pdf. Accessed November 14, 2011.

4. Rural Assistance Center. About rural training tracks. Available at http://www.raconline.org/rtt/about_rtts. php. Accessed October 8, 2011. 